\title{
Differences between remaining ability and loss of capacity in maximum aerobic impairment
}

\author{
J.A. Neder ${ }^{1}$, \\ L.E. Nery ${ }^{1}$, \\ E. Bagatin ${ }^{2}$, \\ S.R. Lucas ${ }^{1}$, \\ M.S. Anção ${ }^{1}$ \\ and D.Y. Sue ${ }^{3}$
}

\author{
'Divisão de Medicina Respiratória, Departamento de Medicina, \\ Escola Paulista de Medicina, Universidade Federal de São Paulo, São Paulo SP, Brasil \\ ${ }^{2}$ Divisão de Medicina Ocupacional, Departamento de Medicina Social e Preventiva, \\ Universidade Estadual de Campinas, Campinas SP, Brasil \\ ${ }^{3}$ Division of Respiratory and Critical Care Physiology and Medicine, \\ Department of Medicine, Harbor-UCLA Medical Center, Torrance, CA, USA
}

Correspondence

L.E. Nery

Disciplina de Pneumologia

EPM, UNIFESP

Rua Botucatu, 740, 30 andar

04023-062 São Paulo, SP

Brasil

Fax: 55 (011) 570-2127

Research partially supported by CNPq and FAPESP. Part of a Doctoral thesis presented by J.A. Neder to the Disciplina de Pneumologia, UNIFESP-EPM.

Received May 21, 1997 Accepted February 13, 1998 $\ldots \ldots \ldots \ldots \ldots \ldots \ldots . . \ldots \ldots$

\section{Abstract}

In the evaluation of exercise intolerance of patients with respiratory diseases the American Medical Association (AMA) and the American Thoracic Society (ATS) have proposed similar classifications for rating aerobic impairment using maximum oxygen uptake $\left(\mathrm{VO}_{2} \max \right)$ normalized for total body weight $\left(\mathrm{ml} \mathrm{min}^{-1} \mathrm{~kg}^{-1}\right)$. However, subjects with the same $\mathrm{VO}_{2}$ max weight-corrected values may have considerably different losses of aerobic performance $\left(\mathrm{VO}_{2}\right.$ max expressed as \% predicted). We have proposed a new, specific method for rating loss of aerobic capacity $\left(\mathrm{VO}_{2} \mathrm{max}, \%\right.$ predicted) and we have compared the two classifications in a prospective study involving 75 silicotic claimants. Logistic regression analysis showed that the disagreement between rating systems (higher dysfunction by the AMA/ATS classification) was associated with age $>50$ years $(\mathrm{P}<0.005)$ and overweight $(\mathrm{P}=0.04)$. Interestingly, clinical (dyspnea score) and spirometric $\left(\mathrm{FEV}_{1}\right)$ normality were only associated with the $\mathrm{VO}_{2} \mathrm{max}, \%$ predicted, normal values $(\mathrm{P}<0.01)$; therefore, in older and obese subjects the AMA/ATS classification tended to overestimate the aerobic dysfunction. We conclude that in the evaluation of aerobic impairment in patients with respiratory diseases, the loss of aerobic capacity $\left(\mathrm{VO}_{2} \mathrm{max}\right.$, $\%$ predicted) should be used instead of the traditional method (remaining aerobic ability, $\mathrm{VO}_{2} \max$, in $\mathrm{ml} \mathrm{min}^{-1} \mathrm{~kg}^{-1}$ ).

\section{Introduction}

Relating the loss of pulmonary function to the degree of exercise intolerance (impairment) $(1,2)$ remains a controversial aspect of occupational medicine $(1,6)$. Complaints of dyspnea in patients with occupation-related pulmonary disorders often exceed objective findings, especially in claimants, and it is
Key words

- Disability evaluation

- Work capacity

- Exercise tolerance

- Oxygen consumption

- Occupational diseases well recognized that accurate assessment of work capacity must consider that subjects may be limited by non-respiratory problems (7). Analysis of metabolic and ventilatory responses during exercise has significantly improved the quality of both occupational and non-occupational respiratory disease evaluation (8). The American Thoracic Society (ATS; 1,2 ) and the American Medical 
Table 1 - Aerobic dysfunction according to a classification for rating remaining ability (AMA/ATS) and a new proposal for rating loss of capacity.

None Mild Moderate Severe

AMA/ATS

$\mathrm{VO}_{2} \max \quad>25 \quad 20-25 \quad 15-20 \quad<15$

( $\mathrm{ml} \mathrm{min} \mathrm{mog}^{-1} \mathrm{~kg}^{-1}$ )

New proposal

$\mathrm{VO}_{2} \max \quad>70 \quad 60-69 \quad 40-59 \quad<40$

(\% predicted)

Association (AMA; 3-5) have proposed similar criteria for rating "remaining aerobic ability", based on maximum oxygen uptake $\left(\mathrm{VO}_{2} \mathrm{max}\right)$ attained in the laboratory. The observed values are normalized by actual weight $\left(\mathrm{ml} \mathrm{min}^{-1} \mathrm{~kg}^{-1}\right)$ allowing comparisons with the estimated work metabolic stress. For example, if an individual's $\mathrm{VO}_{2}$ max is found to be greater than $25 \mathrm{ml} \mathrm{min}{ }^{-1} \mathrm{~kg}^{-1}$, remaining aerobic ability is judged normal using this scheme (Table 1).

Nevertheless, patients with identical measured $\mathrm{VO}_{2}$ max (expressed as $1 /$ min) may demonstrate marked differences between remaining ability $\left(\mathrm{VO}_{2} \max , \mathrm{ml} \mathrm{min}{ }^{-1} \mathrm{~kg}^{-1}\right)$ and loss of capacity ( $\mathrm{VO}_{2} \mathrm{max}, \%$ predicted). A younger, non-obese individual with a high predicted normal $\mathrm{VO}_{2}$ max may have sustained a considerable loss of capacity and yet have a "normal" remaining capacity $\left(\mathrm{VO}_{2} \max >25 \mathrm{ml} \mathrm{min}^{-1} \mathrm{~kg}^{-1}\right)$. On the other hand, an older and especially overweight individual may have an abnormally low $\mathrm{VO}_{2}$ max expressed $\mathrm{ml} \mathrm{min}^{-1} \mathrm{~kg}^{-1}$ even though the loss of aerobic capacity expressed as $\mathrm{VO}_{2}$ max, \% predicted, may be slight. Therefore, rating aerobic dysfunction using only remaining ability $\left(\mathrm{VO}_{2} \max , \mathrm{ml} \mathrm{min}{ }^{-1} \mathrm{~kg}^{-1}\right)$ could lead to major discrepancies when compared to a scheme expressing loss of capacity $\left(\mathrm{VO}_{2} \mathrm{max}, \%\right.$ predicted).

The aim of the present study was to compare conclusions reached by two systems of rating aerobic dysfunction based on $\mathrm{VO}_{2}$ max measured in a heterogeneous group of sili- cotic claimants: 1) a system similar to the AMA/ATS classification (1-5) $\left(\mathrm{VO}_{2} \mathrm{max}, \mathrm{ml}\right.$ $\mathrm{min}^{-1} \mathrm{~kg}^{-1}$ ) and 2) a new system based on reduction of $\mathrm{VO}_{2}$ max values compared to predicted $\left(\mathrm{VO}_{2} \mathrm{max}, \%\right.$ predicted; Table 1$)$. We hypothesized that there would be significant differences between the two systems that could lead to potentially different conclusions about impairment in individual subjects.

\section{Material and Methods}

\section{Subjects and clinical evaluation}

A group of subjects undergoing evaluation was available for comparison of aerobic performance. These claimants with occupational exposure to free silica in the ceramics industry generally had some degree of dyspnea, and had radiographic abnormalities suggestive of silicosis. No patient was excluded due to a co-morbidity factor if the latter was compensated (systemic arterial hypertension, diabetes mellitus). Any medications utilized by the patients were maintained. Informed consent to participate in the study was obtained from all subjects. The protocol was submitted to and approved by the Ethics Committee of UNIFESP/EPM-HSP.

Clinical, occupational and smoking histories were obtained; physical examination and anthropometric evaluation were performed in all subjects. A dyspnea score was recorded using a Cotes modified scale (9) in which a normal degree of respiratory effort was defined as breathlessness occurring while walking uphill or climbing stairs, but not with a lesser degree of exertion. Posteroanterior chest radiographs were interpreted by two experienced readers according to the International Labor Organization (10) classification of radiographs of pneumoconiosis.

Spirometry

Pulmonary function tests were performed 
with a CPF-System (Medical Graphics Corporation (MGC), St. Paul, MN) utilizing a Fleisch-type No. 3 pneumotachograph. Measurements were performed according to standard protocols following ATS guidelines (11), pre- and post-200 $\mu \mathrm{g}$ of salbutamol administered with a metered-dosed inhaler. Forced expiratory volume in $1 \mathrm{~s}\left(\mathrm{FEV}_{1}\right)$ and forced vital capacity (FVC) were recorded in all subjects. Predicted normal values were those of Knudson et al. (12). Maximal voluntary ventilation (MVV) was estimated as the product of $\mathrm{FEV}_{1} \times 40$ (13).

Cardiopulmonary exercise testing

The exercise study was performed with the subject sitting on a calibrated, electromagnetically braked cycle ergometer (CPE2000, MGC). The cycle seat was adjusted for the subjects' comfort. The cycle ergometer was interfaced with a digital computerbased exercise system (CPX-System, MGC) which increased the work rate at a constant rate (ramp protocol). The increase in work rate (10 to 20 watts $/ \mathrm{min}$ ) was chosen in such a way that the symptom-limited maximum was obtained between 8 and $12 \mathrm{~min}$. Subjects breathed through a $115-\mathrm{ml}$ deadspace, low-resistance Hans-Rudolph valve. The expiratory arm of the valve was connected to a Fleisch-type No. 3 pneumotachograph and the flow signal was electronically integrated to obtain volume variables. A $1-\mathrm{ml} / \mathrm{s}$ sample of expired gas from the mouthpiece was drawn for determination of expired $\mathrm{O}_{2}$ and $\mathrm{CO}_{2}$ with a zirconium cell and rapid infrared analyzer, respectively. Gas measurements and flow were analyzed breath-by-breath after phase delay correction (13). All subjects had their heart rate measured and electrocardiogram obtained each minute; subjects were also monitored by pulse oximetry (OxyShuttle ${ }^{\mathrm{TM}}$ SensorMedics, SensorMedics Corp., Anaheim, CA).

The exercise test consisted of measurements of gas exchange and flow at rest for 2 min, 2 min while the subject was pedaling without a load, and then while the work rate was increased until the subject indicated that he could not continue pedaling at least at 50 rpm, or the test was stopped by the attending physician. All subjects were encouraged to perform as long as possible. At the end of exercise, the subject was asked to describe his symptoms and to rate the severity of dyspnea, fatigue and leg pain (modified Borg scale; 14). Exercise could be terminated by the physician if a subject had a fall in systolic blood pressure (BP) of more than $15 \mathrm{mmHg}$, systolic $\mathrm{BP}>250 \mathrm{mmHg}$, diastolic $\mathrm{BP}>120$ $\mathrm{mmHg}$, progressive horizontal or downsloping ST-segment depression, T-wave inversion or the appearance of Q waves, increased frequency of premature ventricular contraction, ventricular tachycardia (3 or more consecutive ectopic beats), onset of atrial fibrillation or atrial tachycardia (15), or pulse oximeter oxyhemoglobin saturation $\left(\mathrm{SaO}_{2}\right)$ $<80 \%$.

The following variables were measured during the test: breath-by-breath $\mathrm{O}_{2}$ uptake $\left(\mathrm{VO}_{2}, \mathrm{ml} / \mathrm{min}\right.$, standard temperature and pressure, dry; STPD), $\mathrm{CO}_{2}$ output $\left(\mathrm{VCO}_{2}, \mathrm{ml} /\right.$ min STPD), respiratory exchange ratio $(\mathrm{R})$, minute ventilation (VE, $1 / \mathrm{min}$, body temperature, ambient pressure, saturated BTPS), breathing frequency (f, bpm), tidal volume (VT, $\mathrm{ml} / \mathrm{min}$ BTPS), ventilatory equivalents for $\mathrm{O}_{2}$ and $\mathrm{CO}_{2}\left(\mathrm{VE} / \mathrm{VO}_{2}, \mathrm{VE} / \mathrm{VCO}_{2}\right)$, endtidal $\mathrm{PO}_{2}$ and $\mathrm{PCO}_{2}\left(\mathrm{PETO}_{2}, \mathrm{PETCO}_{2}\right.$, $\mathrm{mmHg}$ ), dead space/tidal volume ratio (VD/ $\mathrm{VT})$, heart rate (HR, b/min) and oxygen pulse ( $\mathrm{VO}_{2} / \mathrm{HR}, \mathrm{ml} /$ beat $)$.

The $\mathrm{VO}_{2}$ achieved by the subjects at maximal effort, limited by symptoms or by medical reasons, was considered to be the $\mathrm{VO}_{2}$ max (peak $\mathrm{VO}_{2}$ ), and was defined as the highest value obtained in the analysis of 8-breath moving average. $\mathrm{VO}_{2}$ max was expressed as $\%$ predicted according to the reference values of Hansen and coworkers (16): i) in eutrophic and underweight males, the predicted $\mathrm{VO}_{2} \max (\mathrm{ml} / \mathrm{min})$ was calculated us- 
ing the actual weight: weight $(\mathrm{kg}) \times 50.72$ $0.372 \mathrm{x}$ age (years) and, ii) in overweight subjects, the ideal weight normalized for height was used: $\mathrm{VO}_{2} \max =(0.79 \mathrm{x}$ height $(\mathrm{cm})-60.7 \times 50.72-0.372 \times$ age (years).

The anaerobic threshold $\left(\mathrm{VO}_{2} \mathrm{AT}\right)$ was estimated by gas exchange at the point at which $\mathrm{VCO}_{2}$ increased out of proportion to $\mathrm{VO}_{2}$ (V-slope) and when the $\mathrm{VE} / \mathrm{VO}_{2}$ ratio and the $\mathrm{PETO}_{2}$ increased while the ratio VE/ $\mathrm{VCO}_{2}$ and $\mathrm{PETCO}_{2}$ remained constant (13). The lower limit of normality for $\mathrm{VO}_{2} \mathrm{AT}$ was set at $40 \%$ of predicted $\mathrm{VO}_{2} \max (13)$. The reading was performed by two observers who always agreed in their analysis. The

Table 2 - Subject characteristics, pulmonary function and exercise performance.

Results are reported as mean \pm SD for continuous variables and as absolute and $\%$ values, for the others. FVC: Forced vital capacity; FEV : $_{1}$ forced expiratory volume in one second of the $\mathrm{FVC} ; \mathrm{VO}_{2}$ : oxygen consumption; $\mathrm{VO}_{2} \mathrm{AT}$ : oxygen consumption at the anaerobic threshold; HR: heart rate; VE: minute ventilation; MVV: maximal voluntary ventilation; $\mathrm{SaO}_{2}$ : saturation of oxyhemoglobin

\begin{tabular}{|c|c|}
\hline & Total $(N=75)$ \\
\hline Age (years) & $52.2 \pm 9.0$ \\
\hline Actual weight (kg) & $71.9 \pm 12.9$ \\
\hline Height (cm) & $166.2 \pm 7.4$ \\
\hline \multicolumn{2}{|l|}{ Sex } \\
\hline Male & 67 \\
\hline Female & 8 \\
\hline \multicolumn{2}{|l|}{ Smoking history } \\
\hline Never & 34 \\
\hline Former or current & 41 \\
\hline Pack-years of smoking & $20.0 \pm 14.1$ \\
\hline Free-silica exposition (years) & $23.9 \pm 8.2$ \\
\hline \multicolumn{2}{|l|}{ Spirometry } \\
\hline $\mathrm{FEV}_{1}(\mathrm{I})$ & $2.78 \pm 0.82$ \\
\hline $\mathrm{FEV}_{1}(\%$ predicted $)$ & $92.4 \pm 24.1$ \\
\hline FVC (\% predicted) & $102.4 \pm 21.5$ \\
\hline $\mathrm{FEV}_{1}(\%)$ & $73.4 \pm 10.3$ \\
\hline \multicolumn{2}{|l|}{ Maximum exercise (max) } \\
\hline $\mathrm{VO}_{2} \max (\mathrm{ml} / \mathrm{min})$ & $1452.10 \pm 518.07$ \\
\hline $\mathrm{VO}_{2} \max (\%$ predicted $)$ & $70.2 \pm 20.0$ \\
\hline $\mathrm{VO}_{2} \max (\mathrm{ml} \mathrm{min}-1 \mathrm{~kg}-1)$ & $20.3 \pm 7.0$ \\
\hline $\mathrm{VO}_{2} \mathrm{AT}\left(\% \mathrm{VO}_{2}\right.$ max predicted) & d) $44.3 \pm 11.0$ \\
\hline HRmax (\% predicted) & $80.7 \pm 11.8$ \\
\hline $\mathrm{O}_{2}$-Pulse $\max (\mathrm{ml} / \mathrm{b})$ & $10.6 \pm 3.6$ \\
\hline VEmax/MVV & $0.49 \pm 0.15$ \\
\hline $\mathrm{SaO}_{2} \max (\%)$ & $95.2 \pm 1.6$ \\
\hline
\end{tabular}

predicted maximal HR (HRmax) was calculated as 220 - age (13). The chronotropic reserve was calculated by the equation: 1 HRmax/HRpred, and the breathing reserve using the standard equation 1 - VEmax/MVV.

\section{Statistical analysis}

The Kappa reliability test was used to determine the presence of significant concordance between the classifications of aerobic dysfunction. Logistic regression analysis was performed to correlate the demographic and anthropometric variables with the discordance between the classifications. The Mann-Whitney U-test was carried out to contrast excess weight values among groups. To evaluate the associations among some studied variables, we used chi-square analysis (Fisher's exact test). For all tests, a P value $<0.05$ was considered to be statistically significant.

Receiver operating characteristic (ROC) analysis was used to choose an appropriate $\mathrm{VO}_{2}$ max \% predicted cutoff value for comparison to the $\mathrm{VO}_{2}$ max ml min-1 $\mathrm{kg}^{-1}$ criterion and to test the relative accuracy of the two systems (17). A ROC plot consists of a statistical method designed to evaluate the overall relationship between sensitivity and specificity of a test against a selected "gold standard". Assuming a necessary inverse relationship between sensitivity and specificity, the best decision threshold corresponds to the best possible combination of sensitivity and specificity and, therefore, the area under the curve is closely related to the overall accuracy of the test. In this experiment, the selected gold standard was the $\mathrm{VO}_{2} \mathrm{AT}$, a variable that provides a global assessment of aerobic performance independent of effort or of achieving a true $\mathrm{VO}_{2}$ max (13). Thus, a ROC plot was constructed by plotting the true-positive fraction (sensitivity) against the false-positive fraction (1-specificity) for multiple $\mathrm{VO}_{2}$ max decision thresholds using discrete test values (17). 


\section{Results}

Seventy-five subjects (67 males and 8 females) participated. Mean age was 52.2 years and many subjects had a history of smoking. Fifty-eight subjects ( 55 males and 3 females) were classified as having small opacities and 17 ( 12 males and 5 females) as having large opacities by roentgenographic analysis (10). Clinical, spirometric and exercise findings are presented in Table 2.

In the new classification, the lower limit of normality $\left(70 \%\right.$ of predicted $\mathrm{VO}_{2}$ max $)$ was the best possible combination between sensitivity and specificity changing the $\mathrm{VO}_{2} \mathrm{max} \%$ predicted values against the gold standard $\left(\mathrm{VO}_{2} \mathrm{AT}\right)$. Thus, the point closest to the upper left corner of Figure 1 was selected as the best cutoff for normality for the new method.

In a global comparison between the two schemes, we found that of 75 studied subjects, only $19(25.3 \%)$ were classified as normal by the AMA/ATS criteria $\left(\mathrm{VO}_{2}\right.$ max $>25 \mathrm{ml} \mathrm{min} \mathrm{kg}^{-1} \mathrm{~kg}^{-1}$. On the other hand, 40 of 75 subjects $(53.3 \%)$ had a $\mathrm{VO}_{2} \max >70 \%$ predicted (no loss of aerobic capacity), including 21 of 56 subjects with $\mathrm{VO}_{2}$ max $<25$ $\mathrm{ml} \mathrm{min}{ }^{-1} \mathrm{~kg}^{-1}$. No subject with $\mathrm{VO}_{2} \max >25$ $\mathrm{ml} \mathrm{min}{ }^{-1} \mathrm{~kg}^{-1}$ had a $\mathrm{VO}_{2}$ max $<70 \%$ predicted (Table 3).

We anticipated that age might have an impact on the different schemes due to the generally lower predicted $\mathrm{VO}_{2}$ max in older subjects (above 50 years). As shown in Table 3 , there was a significant difference regarding the gradation of aerobic dysfunction just in the older group $(\mathrm{k}=0.03, \mathrm{P}=0.29)$. Among patients older than 50 years (group II), of 22 patients with $\mathrm{VO}_{2} \max >70 \%$ predicted, only 5 (22.7\%) had normal remaining aerobic ability. Furthermore, only 4 of these older subjects were considered to have severe functional loss $\left(\mathrm{VO}_{2} \max <40 \%\right.$ predicted), compared to 17 classified as severe on the basis of $\mathrm{VO}_{2} \max <15 \mathrm{ml} \mathrm{min}^{-1} \mathrm{~kg}^{-1}$. Therefore, in patients $>50$ years old, $\mathrm{VO}_{2}$ max expressed as $\mathrm{ml} \mathrm{min}^{-1} \mathrm{~kg}^{-1}$ frequently suggested a lower remaining ability compared to the milder degree of loss of capacity found by looking at $\mathrm{VO}_{2} \max \%$ predicted. In summary, the interpretation of the two $\mathrm{VO}_{2} \max$ analyses was concordant for $61 \%$ of subjects younger than 50 years as opposed to only $23 \%$ of 44 older subjects (Table 3 ).

We also hypothesized that overweight individuals would be more likely to show a difference between the two schemes. Those subjects who showed concordance for $\mathrm{VO}_{2} \max$ (normal or abnormal for both meth-

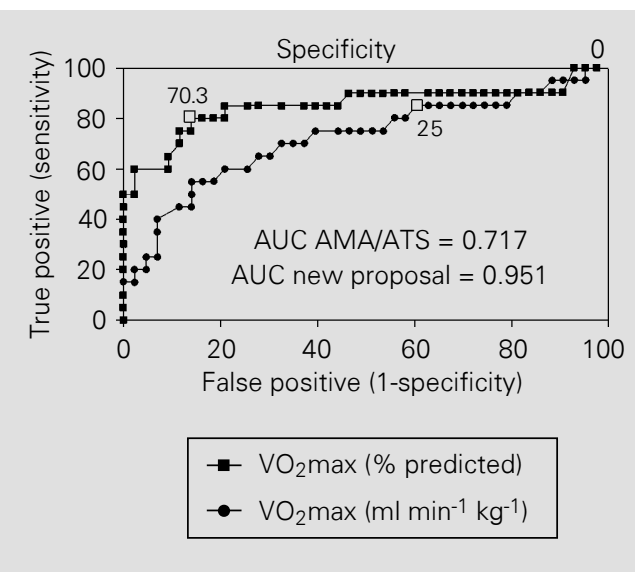

Figure 1 - Receiver operating characteristics (ROC) curves of the two classifications, using the $\mathrm{VO}_{2}$ at the anaerobic threshold $\left(\mathrm{VO}_{2} \mathrm{AT}\right)$ as the "gold standard" for aerobic dysfunction. Open squares, Cutoffs of normality for $\mathrm{VO}_{2}$ max regarding to the two classifications; $A \cup C=$ area under the ROC curve.
Table 3 - Concordance between classifications of aerobic function: remaining ability $\left(\mathrm{VO}_{2}\right.$ max, $\left.\mathrm{ml} \mathrm{min}{ }^{-1} \mathrm{~kg}^{-1}\right)$ and loss of capacity $\left(\mathrm{VO}_{2} \max , \%\right.$ predicted).

Group I = age $<50$ years; group $I I=$ age $>50$ years. ${ }^{+}$Significant concordance $(P<0.0001$; $k=0.40$, Kappa reliability test). ${ }^{++}$Nonsignificant concordance $(P=0.29 ; k=0.03$, Kappa reliability test).

\begin{tabular}{|c|c|c|c|c|c|}
\hline \multirow[b]{2}{*}{$\begin{array}{l}\text { New proposal } \\
\text { (\% predicted) }\end{array}$} & \multicolumn{5}{|c|}{ AMA/ATS (ml min-1 $\left.\mathrm{kg}^{-1}\right)$} \\
\hline & $\begin{array}{l}\text { None } \\
(>25)\end{array}$ & $\begin{array}{l}\text { Mild } \\
(20-25)\end{array}$ & $\begin{array}{l}\text { Moderate } \\
(15-20)\end{array}$ & $\begin{array}{l}\text { Severe } \\
(<15)\end{array}$ & Total \\
\hline & \multicolumn{5}{|c|}{ Group I $(\mathrm{N}=31)^{+}$} \\
\hline None $(\geq 70)$ & 14 & 3 & - & 1 & 18 \\
\hline Mild (60-69) & - & 2 & 2 & 2 & 6 \\
\hline Moderate (40-59) & - & 2 & 2 & 1 & 5 \\
\hline Severe $(<40)$ & - & - & 1 & 1 & 2 \\
\hline \multirow[t]{2}{*}{ Total } & 14 & 7 & 5 & 5 & 31 \\
\hline & \multicolumn{5}{|c|}{ Group II $(\mathrm{N}=44)^{++}$} \\
\hline None $(\geq 70)$ & 5 & 7 & 8 & 2 & 22 \\
\hline Mild (60-69) & - & - & 6 & 2 & 8 \\
\hline Moderate (40-49) & - & - & 1 & 9 & 10 \\
\hline Severe $(<40)$ & - & - & - & 4 & 4 \\
\hline Total & 5 & 7 & 15 & 17 & 44 \\
\hline
\end{tabular}


Figure 2 - Weight excess (actual weight minus ideal weight) for subjects younger than and older than 50 years who had concordance for $\mathrm{VO}_{2}$ max, $\mathrm{ml} \mathrm{min}^{-1} \mathrm{~kg}^{-1}$ and $\mathrm{VO}_{2} \max$, \% predicted (normal and concordant or abnormal and concordant (conc.)) or lack of concordance by the two methods (discordant (disc.)). Numbers above block are mean weight in excess of ideal weight. ${ }^{*} \mathrm{P}<0.05$ $<50$ years conc. vs disc.; ${ }^{*} \mathrm{P}<0.01$, $>50$ years conc. vs disc. (MannWhitney U-test).

Figure 3 - Percentage of subjects with normal $\mathrm{VO}_{2}$ max expressed as $\mathrm{ml} \mathrm{min} \mathrm{m}^{-1} \mathrm{~kg}^{-1}$ or $\mathrm{VO}_{2}$ max as \% predicted for subjects older than 50 years who had a normal dyspnea score $(<1)$ or normal $\mathrm{FEV}_{1}$ (above lower 95\% confidence interval). ${ }^{*} \mathrm{P}=0.01 ;{ }^{*} \mathrm{P}<0.00001$ (Fisher's exact test).

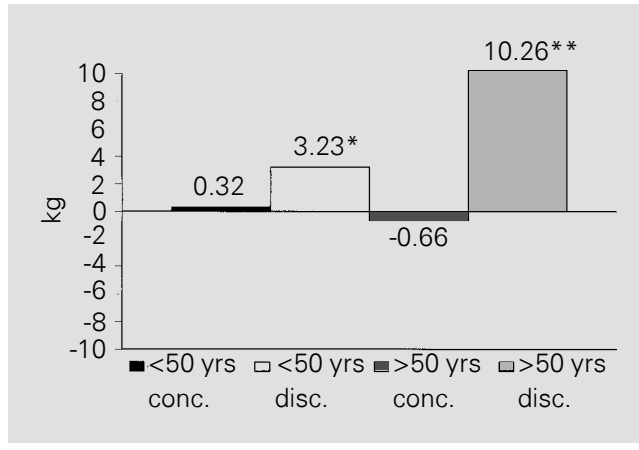

ods of analysis) were as a group closer to normal body weight than those who were discordant, and this was true for both younger and older subjects (Figure 2). Using a logistic regression analysis that considered disagreement between the classifications as dependent event and demographic and anthropometric variables as independent variables, only age and actual weight contributed to explaining the discordance (age, $\mathrm{P}=$ 0.0006; actual weight, $\mathrm{P}=0.04$; $\operatorname{sex}, \mathrm{P}=0.15$; height, $\mathrm{P}=0.84$ ).

We also compared the normality suggested by the two classifications with that indicated by a clinical (dyspnea score) and respiratory function $\left(\mathrm{FEV}_{1}\right.$ above lower $95 \%$ confidence limit) indicator. In older subjects (group II), a significant association was found between the absence of functional loss $\left(\mathrm{VO}_{2} \mathrm{max}>70 \%\right.$ predicted) and a dyspnea score $<1$ and a normal $\mathrm{FEV}_{1}$. A similar relationship between these variables and $\mathrm{VO}_{2} \max$ $\left(\mathrm{ml} \mathrm{min}{ }^{-1} \mathrm{~kg}^{-1}\right.$ ) was not found (Figure 3).

Finally, a direct comparison between

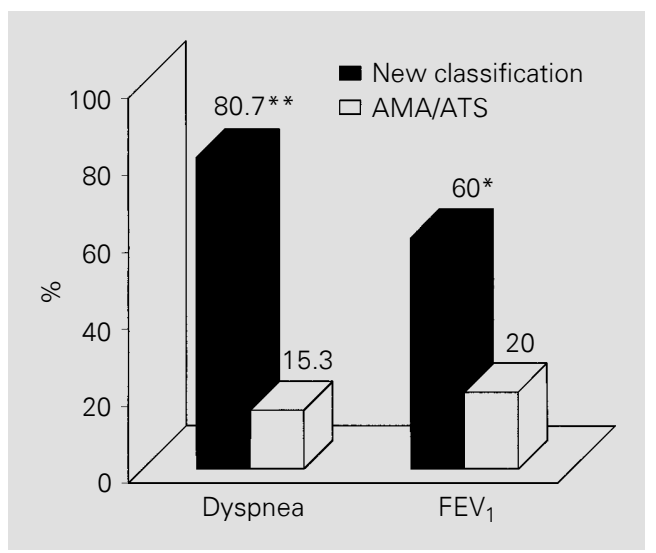

ROC curves and the areas under the curves demonstrated a better performance of the new proposal $\left(\mathrm{VO}_{2} \mathrm{max}, \%\right.$ predicted) compared to current recommendations $\left(\mathrm{VO}_{2} \max\right.$, $\mathrm{ml} \mathrm{min}{ }^{-1} \mathrm{~kg}^{-1}$ ) (Figure 1). In addition, contrasting the lower limits of normality according to the two classifications showed a significant gain in specificity using the $70 \%$ value of $\mathrm{VO}_{2}$ max predicted. Thus, while sensitivity remained unaltered, the new proposal allowed an improvement in specificity from $32.6 \%$ to $70 \%$ with a likelihood ratio increasing from 1.26 to 4.06 (Figure 1).

\section{Discussion}

In this comparative study of two ways of expressing aerobic dysfunction $\left(\mathrm{VO}_{2} \max\right.$, $\mathrm{ml} \mathrm{min}{ }^{-1} \mathrm{~kg}^{-1}$, and $\mathrm{VO}_{2}$ max, \% predicted) in a group of silicotic claimants, we found important disagreement in classifying normal subjects and in estimating the degree of abnormality. In particular, for subjects older than 50 years and for overweight subjects (actual weight above the ideal weight for height), using $\mathrm{VO}_{2} \max \left(\mathrm{ml} \mathrm{min}^{-1} \mathrm{~kg}^{-1}\right)$ would frequently lead to the conclusion of a greater aerobic dysfunction than when using the $\mathrm{VO}_{2}$ max \% predicted expression. Our findings suggest that the present recommendations for rating aerobic dysfunction in pulmonary patients could cause considerable misinterpretation about the presence and degree of impairment.

Work-related respiratory limitation of exercise has long been quantified in classifications of aerobic dysfunction, usually by correcting the $\mathrm{VO}_{2} \max$ values for body weight $(1-5,18,19)$. The basic premise for the use of $\mathrm{VO}_{2} \max \left(\mathrm{ml} \mathrm{min}{ }^{-1} \mathrm{~kg}^{-1}\right)$ to assess impairment is that it allows an immediate comparison with the metabolic demands of the job, therefore providing an answer to the presumed main question: what is the residual ability of the worker in performing his task with comfort and safety? This traditional approach based only on remaining 
ability is appropriate for job placement or "fitness-for-duty evaluations", but ignores the potential physiological importance of loss of aerobic capacity.

Our results indicated that recommendations based on $\mathrm{VO}_{2} \max \left(\mathrm{ml} \mathrm{min}{ }^{-1} \mathrm{~kg}^{-1}\right)$ can be significantly different from a classification based on loss of aerobic capacity (Table $3)$. The disagreement between the classifications is particularly noticeable in older and heavier individuals. Thus, in those older than 50 years, with low absolute $\mathrm{VO}_{2}$ max values $(1 / \mathrm{min})$, the actual weight correction in overweight individuals led to lower remaining ability than functional loss. In these patients, the loss of aerobic capacity was proportionally small in view of their low predicted values. These findings are particularly important considering that this demographic and anthropometric profile is the most prevalent in claimants with respiratory diseases (20).

$\mathrm{VO}_{2}$ max normalization for actual weight ${ }^{-1}$, a common procedure in sports medicine, should be justifiable only in activities where the total dynamic displacement of the body is the rule (fast walking, running) (21) and not the exception, as in most industrial plants and extractive sites (22). In activities without active body movement, such as short distance walking, cycling and weight lifting, the normalization of actual weight for height (ideal weight) would prevent the overestimation of the predicted values of $\mathrm{VO}_{2}$ max in overweight subjects (16).

The lower limit of normality established by the new proposal $(70 \%$ of predicted $\mathrm{VO}_{2}$ max) was a best decision threshold obtained from a ROC curve constructed with $\mathrm{VO}_{2} \mathrm{AT}$ as the criterion for aerobic dysfunction (Figure 1). $\mathrm{VO}_{2} \mathrm{AT}$ is defined as the level of exercise $\mathrm{VO}_{2}$ above which oxidative-based energy production is overlapped by anaerobic mechanisms. Typically, this is associated with increases in blood lactate, ventilatory and cardiac responses, catecholamine release, and a reduction of endurance time (13). Furthermore, the effort-independent characteristic of this parameter is especially interesting for the aerobic evaluation of claimants (23). The intermediate impairment cutoffs follow those usually recommended for pulmonary function tests (11). The limit of severe aerobic impairment was established at $40 \%$ of predicted $\mathrm{VO}_{2} \mathrm{max}$ considering that it is the lower limit of normality for $\mathrm{VO}_{2} \mathrm{AT}$ (16). Thus, if a claimant shows a $\mathrm{VO}_{2}$ max below this value, obviously his $\mathrm{VO}_{2} \mathrm{AT}$ will be very low and he is likely to utilize predominantly unsustainable anaerobic sources of energy in his activities.

Usually, the validation of a classification of aerobic dysfunction for occupational purposes is done in comparison with ergonomic assumptions. In order to use a less controversial criterion, we compared the normality detected by the two tested schemes with a clinical score of dyspnea (9), and a measure of ventilatory limitation at rest $\left(\mathrm{FEV}_{1}\right)(11)$. The significantly stronger association between normality detected by the new proposal $\left(\mathrm{VO}_{2} \mathrm{max}>70 \%\right.$ predicted) and that suggested by such parameters (Figure 3 ) indicated that a large number of patients over 50 years and overweight were incorrectly considered impaired on the basis of the present recommendations.

The utilization of $\mathrm{VO}_{2} \mathrm{AT}$ as a gold standard of aerobic dysfunction in a ROC analysis permitted a comparison of the two classifications along the entire spectrum of possible decision thresholds. The visual inspection of the curves and the direct comparison between the cutoff points of normality suggested by the two classifications showed a significant gain in specificity in the new proposal with the sensitivity of the AMA/ ATS scheme being maintained. When we analyzed the points on the ROC curves above $60 \%$ sensitivity and specificity we observed a striking superiority of $\mathrm{VO}_{2}$ max expressed as $\%$ of predicted values (Figure 1). These findings are consistent with the tendency of excessive false-positive rates for aerobic ab- 
normality obtained when using the AMA/ ATS classification $\left(\mathrm{ml} \mathrm{min} \mathrm{mg}^{-1} \mathrm{~kg}^{-1}\right)$.

In conclusion, our data indicate that in the assessment of aerobic dysfunction in pulmonary patients, loss of aerobic capacity expressed as $\mathrm{VO}_{2}$ max \% predicted should be an important parameter to be considered in the evaluation of potential impairment. Thus, instead of the comparison with the metabolic requirements of the work (remaining aerobic ability, $\mathrm{VO}_{2}$ max in $\mathrm{ml} \mathrm{min}^{-1} \mathrm{~kg}^{-1}$ or $\mathrm{l} /$ min), loss of capacity should be considered to optimize the maximum $\mathrm{VO}_{2}$ analysis. However, additional research is necessary to evaluate whether or not these findings are also applicable to normal aged overweight subjects.

\section{Acknowledgments}

The authors thank Profs. Neil F. Novo and Adauto Castelo Filho, Universidade Federal de São Paulo, Escola Paulista de Medicina, for their help with the statistical analysis.

\section{References}

1. American Thoracic Society (1982). Evaluation of impairment/disability secondary to respiratory disease. American Review of Respiratory Diseases, 126: 945-951.

2. American Thoracic Society (1986). Evaluation of impairment/disability secondary to respiratory disorders. American Review of Respiratory Diseases, 133: 12051209.

3. American Medical Association (1984). The respiratory system. In: Guides to the Evaluation of Permanent Impairment. 2nd edn. AMA, Chicago, 85-101.

4. American Medical Association (1988). The respiratory system. In: Guides to the Evaluation of Permanent Impairment. 3rd edn. AMA, Chicago, 107-118.

5. American Medical Association (1993). The respiratory system. In: Guides to the Evaluation of Permanent Impairment. 4th edn. AMA, Chicago, 317-326.

6. Harber $P$ \& Fedoruk MJ (1994). Work placement and worker fitness: implications of the Americans with Disabilities Act for pulmonary medicine. Chest, 105: 1564-1571.

7. Agostoni $P$, Smith DD \& Schoene RGB (1987). Evaluation of breathlessness in asbestos workers: results of exercise testing. American Review of Respiratory Diseases, 135: 812-816.

8. Oren A, Sue DY, Hansen JE, Torrance DJ \& Wasserman K (1987). The role of exer- cise testing in impairment evaluation. American Review of Respiratory Diseases, 135: 230-235.

9. Cotes JE (1975). Assessment of disablement due to impaired respiratory function. Bulletin Europeen de Physiopathologie Respiratoire, 11: 210P-217P.

10. International Labour Office (1980). Classification of Radiographics of the Pneumoconiosis. ILO Publications, Geneva.

11. American Thoracic Society (1991). Lung function testing. Selection of reference values and interpretative strategies. American Review of Respiratory Diseases, 144: 1202-1218.

12. Knudson RJ, Lebowitz MD, Holberg CJ \& Burrows B (1976). The maximal expiratory flow volume curve. Normal standards, variability, and effects of age. American Review of Respiratory Diseases, 113: 587-600.

13. Wasserman K, Hansen JE, Sue DY, Whipp BJ \& Casaburi R (1994). Principles of EXercise Testing and Interpretation. 2nd edn. Lea \& Febiger, Philadelphia.

14. Borg G (1990). Psychophysical scaling with applications in physical work and perception of exertion. Scandinavian Journal of Work, Environment and Health, 16: 55108.

15. American College of Sports Medicine (1986). Guidelines for Exercise Testing and Prescription. 3rd edn. Lea \& Febiger,
Philadelphia.

16. Hansen JE, Sue DY \& Wasserman K (1984). Predicted values for clinical exercise testing. American Review of Respiratory Diseases, 129 (Suppl): S49-S55.

17. Zweig MH \& Campbell G (1993). Receiveroperating characteristic (ROC) plots: a fundamental evaluation tool in clinical medicine. Clinical Chemistry, 39: 561-577.

18. Ostiguy GL (1979). Summary of task force report on occupational respiratory disease (pneumoconiosis). Canadian Medical Association Journal, 121: 414-421.

19. Cotes JE, Chinn DJ, Reed JW \& Hutchinson JE (1994). Experience of a standardized method for assessing respiratory disability. European Respiratory Journal, 7: 1074-1076.

20. Harber P \& Rothenberg LS (1986). Controversial aspects of respiratory disability determination. Seminars in Respiratory Medicine, 7: 257-269.

21. Ästrand P-O (1976). Quantification of exercise capability and evaluation of physical capacity in man. Prognosis in Cardiovascular Diseases, 19: 51-67.

22. Harber P, Tamimie J \& Emory J (1984) Estimation of the exertion requirements of coal mining work. Chest, 85: 226-231.

23. Sue DY (1994). Exercise testing in the evaluation of impairment and disability. Clinics in Chest Medicine, 15: 369-387. 